\title{
Deep hand tube-well water for achieving sustainable development goal in arsenic affected villages: Bangladesh experience
}

\author{
B.A. Hoque ${ }^{1}$, S. Khanam ${ }^{1}$, M.A. Zahid ${ }^{1}$, M.M. Hoque ${ }^{1}$, N. Akter ${ }^{2}$, \\ M.N. Mahmud ${ }^{2}$, S. Huque ${ }^{1} \&$ S. Ahmed ${ }^{1}$ \\ ${ }^{1}$ Environment and Population Research Centre (EPRC), Dhaka, Bangladesh \\ ${ }^{2}$ UNICEF Bangladesh, Dhaka, Bangladesh
}

\begin{abstract}
Arsenic mitigation rural water supply is a continued challenge in developing countries. Here we present data in water supply through highly demanded community-level deep hand tube-well (DTW) and discuss perspectives for achieving Sustainable Development Goal (SDG-6.1) in rural Bangladesh. Equity in access to the DTWs was addressed by applying GPS for distance between DTWs and houses of about 34,500 beneficiaries. About $95 \%$ and $50 \%$ of the water point water samples respectively conformed 1) arsenic and bacteriological, and ii) arsenic, bacteriological, manganese and iron quality standards of Bangladesh. Improved technology/hand pump at premises reduced to about $5 \%$ from $50 \%$. Safely managed drinking water service after the SDG-6.1 remained questionable. Research on comprehensive program for safely managed pipe water, appropriate technologies and other issues towards SDG recommended.
\end{abstract}

\section{INTRODUCTION}

Consumption of arsenic contaminated water has been a public health problem among hundreds of millions of population in Asia and other countries (Shankar et al., 2014; Jack et al., 2003). Smith et al. (2000) claimed more than 1.5 decades ago, that Bangladesh had 'the largest mass poisoning of a population in history because groundwater used for drinking has been contaminated with naturally occurring inorganic arsenic'. Although the country has reached MDG drinking water target (UNICEF and WHO, 2015); in 2013 more than 19 million populations (12.4\%) were exposed to the risks of drinking arsenic contaminated water (BBS and UNICEF, 2015). The population exposed to arsenic contaminated water reduced 1.0 percentage point from 2009 to 2013. Community-level hand deep tubewell (DTW) has been the predominant and people's most in-demand arsenic mitigation technology in rural Bangladesh (Bilqis et al., 2006; Kundu et al., 2016; Ravenscroft et al., 2014). Most of the DTWs provided with arsenic and bacteriological/fecal contamination safe water (BBS and UNICEF, 2015; Bilqis et al., 2006). Inequitable distribution of DTWs has been a common problem (Geen et al., 2016).

Here we have presented our experiences gained in scopes of DTW based arsenic mitigation water supply in SDG 6.1 perspectives, particularly under safely managed safe drinking water and updated 'JMP ladders for drinking water'.

\section{METHODS/EXPERIMENTAL}

An action research on community-based arsenic safe drinking water supply was conducted among approximately 0.2 million rural populations of 10 Unions in Narail district by EPRC in collaboration with UNICEF-Bangladesh and DPHE. The project was funded by Embassy of The Netherlands in Bangladesh. One of the main objectives of the project was to create access to safe drinking water among identified worst arsenic exposed approximately 55,000 populations. The screening was done from November' 13 to January 2014. One group of the volunteers ( 01 male \& 01 female) visited every house with a tubewell in a village and conducted the arsenic test on tubewell water sample. They painted arsenic safe $\left(\leq 0.05 \mathrm{mg} \mathrm{L}^{-1}\right.$ arsenic) tubewells with green color and arsenic unsafe ( $>0.05 \mathrm{mg} \mathrm{L}^{-1}$ arsenic) tubewells red based on the test results. Project officers measured GPS values of every tested tubewell and randomly checked about $5 \%$ of the results. Out of the 144 project villages in the 10 Unions approximately 75 worst arsenic affected villages were selected initially for priority water services based on arsenic screening and baseline results. Then the households, with local women, were demarked into a preliminary cluster based on all/majority households which did not meet the UNICEF suggested $150 \mathrm{~m}$ access to safe drinking water device. A cluster included about 20 households per arsenic DTW. 
According to the Bangladesh national strategies, Chairmen of Union Councils take final decision on sites proposed for improved water technologies based on needs. The arsenic screening results, maps and lists of the proposed DTW sites were sent to every Union Council for their necessary actions and approval. The lists of the proposed sites were prepared by project officers, with the local women and men, based on the following project criteria for site and technology selection: families in the cluster do not have access to a safe drinking water technology within $150 \mathrm{~m}$, community (women-led) chosen DTW sites, about 20 families per DTW/cluster, poor and vulnerable families and technical feasibility. Maps on proposed and installed DTW sites were prepared for every Union/village as shown in Figure 1.

Arsenic in water point samples were measured by ECONO quick arsenic test kit supplied by UNICEF. Membrane filter technique by Potatest was used to measure fecal coliform bacteria (cfu $100 \mathrm{~mL}$ ) in the sites.

Here we present a selected part of the data related to arsenic safe 343 DTWs (>150 m depth) installed by the project and construction completed about one month before the water quality measurement.

\section{RESULTS AND DISCUSSION}

\subsection{Equity and conflict resolution}

Overall, about $61 \%$ of the screened TWs were found contaminated with $>0.05 \mathrm{mg} \mathrm{L}^{-1}$ arsenic (Bangladesh standard) and $73.8 \%$ when the reference value is $>0.01 \mathrm{mg} \mathrm{L}^{-1}$ (WHO) standard. The demand for deep tubewells was very high and led to serious conflicts on the proposed potential sites among local leaders, influential families and potential beneficiaries. Most of the members and chairmen of the Union Councils and other leaders were not willing to accept/approve the proposed sites submitted to them by the project and local communities. Also they were not happy that women were given the leading roles in site selection. As a consequence, they threatened to stop the project activities. The project team met with the authorities, chairmen and leaders to discuss/show papers on project objectives, government approved criteria for equitable access to water technology, contamination distribution, the documents on proposed sites with arsenic values and GPS maps. The participants to the meeting being convinced with the used criteria and GPS maps, agreed to the proposed sites and the project was smoothly completed.

\subsection{Collection time}

Here $150 \mathrm{~m}$ criteria were adopted for maximum distance between households and DTWs in a cluster as suggested by UNICEF. Collection time between households and project installed DTWs were found within 30 minutes, when measured in about randomly selected $30 \%$ of the clusters.

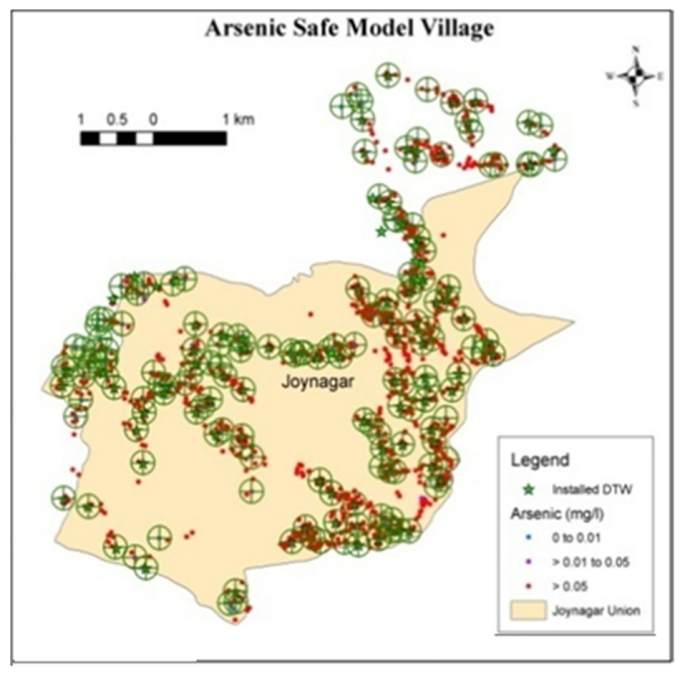

Figure 1. The documents on proposed sites with arsenic values and GPS map.

\subsection{Location on premises}

The rate of households with a shallow or deep tubewell at premises was about $50 \%$ before the intervention. $85 \%$ of the owners of those tube-wells claimed that they could collect water any time and felt safe; though water from about half of those tube-wells had arsenic and/or bacteriological contamination. The rate with the DTWs at premises reduced 5\% after the intervention. One-third of the DTW users reported that they felt safe to collect water any time.

\subsection{Water quality}

Out of the 344 arsenic safe DTWs by Bangladesh standard $\left(0.05 \mathrm{mg} \mathrm{L}^{-1}\right)$, water samples from $94.5 \%$ conformed Bangladesh standard on fecal contamination $(0 \mathrm{cfu}$ per $100 \mathrm{~mL})$. WHO guideline values (combined arsenic and fecal coliform) were met in water samples of $90.1 \%$ DTWs.

Bangladesh has water quality standards for manganese and iron. Water samples from $51 \%$ of DTWs conformed to Bangladesh standards against arsenic, fecal coliform, iron and manganese. WHO guideline does not show health risk values for Manganese and Iron. Here the significant differences in values between water quality (for the four parameters) by Bangladesh standards and WHO guideline values may create confusions on the achievements.

Approximately $90 \%$ of the DTWs beneficiaries (households) reported that they stored the drinking water overnight or more hours. $57 \%$ of the stored water samples from the DTWs with 0 cfu per $100 \mathrm{~mL}$ count at water discharge point were found contaminated. Bacteriological contamination of water between technology/supply point and household storage points have been reported earlier. Chlorination and other disinfection methods can control risks of bacteriological 
contamination at supply and consumption points. An earlier study on regular chlorination at household level in a part of the same area (kalia) was not appreciated by the same community. They preferred chlorination with pipe water supply (Bilqis et al., 2005).

\section{CONCLUSIONS AND RECOMMENDATIONS}

The objective about creating equitable access to improved drinking water technology through deep tube-wells in terms of safe arsenic and free from fecal contamination conditions was achieved (95\%). The results met the 'basic' level of SDG. The equity in the service and undue conflict resolutions were realized at community level by developing and implementing the innovative technique incorporating GPS coordinates with arsenic values and common/poor beneficiaries, leaders, politicians other locations. The results showed significant questions and policy gaps in regard to 'safely managed' level. Also the risk for exposure to the drinking of bacteriological contaminated water at consumption point (from storage container) remained very high.

We recommend research on comprehensive program for safely managed pipe water, communitybased appropriate technologies, gaps between national and international issues, women in decision making, policy and other related aspects towards SDG.

\section{ACKNOWLEDGEMENTS}

We acknowledge Narail people and the administration for participation and support. We sincerely thank P. Ravenscroft, M. Bolton, Hrachya Sargsyan, M.S. Rahman, M. Slotema, Khaleduzzaman, M. Siddik, A. Rahman and other colleagues from UNICEF, DPHE, Dutch Embassy and EPRC for their contributions to the project.

\section{REFERENCES}

BBS \& UNICEF 2015. Multiple indicator cluster survey. Progotir Pathey, 2012-2013, Government of the People's Republic of Bangladesh.

Bilqis, A.H., Khanam, S. \& Motin, A. 2005. Assessment and management of risks in supply of safe drinking water through alternative water supply options in arsenic affected area. Report submitted to UNICEF \& DFID by EPRC.

Bilqis, A.H., Yamaura, S., Sakai, A., Khanam, S., Mahbooba, K., Yamen, H., Sanowar, H., Islam, S. \& Obaid, H. 2006. Arsenic mitigation for water supply in Bangladesh: appropriate technological and policy perspectives. Water Qual. Res. J. Can. 41(2): 226-234.

Geen, A.V., Ahmed, K.M., Ahmed, E.B., Choudhury, I., Mozumder, M.R., Bostick, B.C. \& Mailloux, B.J. 2016. Inequitable allocation of deep community wells for reducing arsenic exposure in Bangladesh. J. Water Sanit. Hyg. Dev. 6(1): 142-150.

Jack, C.N., Wang, J. \& Shraim, A. 2003. A global health problem caused by arsenic from natural sources. Chemosphere 52(9): 1353-1359.

Kundu, D.K., Bas, J.M., Vliet, V. \& Aarti, G. 2016. The consolidation of deep tube well technology in safe drinking water provision: the case of arsenic mitigation in rural Bangladesh. Asian J. Technol. Innov. 24(2): 254-273.

Ravenscroft, P., Kabir, A., Hakim, S.A.I., Ibrahim, A.K.M., Ghosh, S.K., Rahman, M.S., Akter, F. \& Sattar, M.A. 2014. Effectiveness of public rural water points in Bangladesh with special reference to arsenic mitigation. J. Water Sanit. Hyg. Dev. 4(4): 545-562.

Shankar, S., Shanker, U. \& Shikha. 2014. Arsenic contamination of groundwater: a review of sources, prevalence, health risks, and strategies for mitigation. The Scientific World Journal, 304524.

Smith, A.H., Lingas, E.O. \& Rahman, M. 2000. Contamination of drinking-water by arsenic in Bangladesh: a public health emergency. Bull. World Health Organ. 78(9): 1093-1103.

UNICEF and World Health Organization (WHO) 2015. Progress on sanitation and drinking water - 2015 update and MDG assessment. WHO Press, World Health Organization, Geneva, Switzerland, 80p. 